\title{
Phosphorylation of the translation initiation factor elF2 $a$ at serine 51 determines the cell fate decisions of Akt in response to oxidative stress
}

\author{
K Rajesh ${ }^{1}$, J Krishnamoorthy ${ }^{1}$, U Kazimierczak ${ }^{1,2}$, C Tenkerian ${ }^{1,3}$, Al Papadakis ${ }^{4}$, S Wang ${ }^{1}$, S Huang ${ }^{4}$ and AE Koromilas ${ }^{\star, 1,5}$
}

Phosphorylation of the $\alpha$ subunit of the translation initiation factor elF2 at serine 51 (elF2 $\alpha \mathrm{P}$ ) is a master regulator of cell adaptation to various forms of stress with implications in antitumor treatments with chemotherapeutic drugs. Herein, we demonstrate that genetic loss of the elF2 $\alpha$ kinases PERK and GCN2 or impaired elF2 $\alpha$ P by genetic means renders immortalized mouse fibroblasts as well as human tumor cells increasingly susceptible to death by oxidative stress. We also show that elF2 $\alpha \mathrm{P}$ facilitates Akt activation in cells subjected to oxidative insults. However, whereas Akt activation has a pro-survival role in elF2 $\alpha \mathrm{P}$ proficient cells, the lesser amount of activated Akt in elF2 $\alpha$ P-deficient cells promotes death. At the molecular level, we demonstrate that elF2 $\alpha \mathrm{P}$ acts through an ATF4-independent mechanism to control Akt activity via the regulation of mTORC1. Specifically, elF2 $\alpha$ P downregulates mTORC1 activity, which in turn relieves the feedback inhibition of PI3K resulting in the upregulation of the mTORC2-Akt arm. Inhibition of mTORC1 by rapamycin restores Akt activity in elF2 $\alpha$ P-deficient cells but renders them highly susceptible to Akt-mediated death by oxidative stress. Our data demonstrate that elF2 $\alpha \mathrm{P}$ acts as a molecular switch that dictates either cell survival or death by activated Akt in response to oxidative stress. Hence, we propose that inactivation of elF2 $\alpha \mathrm{P}$ may be a suitable approach to unleash the killing power of Akt in tumor cells treated with pro-oxidant drugs.

Cell Death and Disease (2015) 6, e1591; doi:10.1038/cddis.2014.554; published online 15 January 2015

Oxidative stress is a common form of stress caused by the generation of reactive oxygen species (ROS), which are byproducts of oxidative protein folding, mitochondrial respiration and detoxification. ${ }^{1}$ Oxidative stress results in the induction of several intracellular pathways owing to the activation of receptor tyrosine kinases and/or inactivation of phosphatases in order to facilitate either cell survival or death. ${ }^{1}$ A key pathway induced by oxidative stress is the phosphatidylinositol 3-kinase (PI3K)-Akt/PKB pathway owing to either the activation of the epidermal growth factor receptor (EGFR) or inactivation of the phosphatase and tensin homolog deleted in chromosome 10 (PTEN). ${ }^{2}$ Akt activity is induced by phosphorylation at threonine (T) 308 and serine (S) 473 mediated by the PI3K-dependent kinase 1 (PDK1) and the mammalian target of rapamycin complex 2 (mTORC2) kinase, respectively. ${ }^{3}$ Many studies have shown that activated Akt assumes a prosurvival role in cells exposed to oxidative insults. ${ }^{4-12}$ More recent studies, however, revealed an unusual function of Akt, which is its ability to increase the synthesis of intracellular ROS and inhibit proliferation through the induction of either premature senescence or cell death. ${ }^{13-17}$
An immediate response of cells exposed to various forms of stress is the general inhibition of protein synthesis, which is mainly caused by the increased phosphorylation of the a subunit of the translation initiation factor elF2a at S51 (herein referred to as elF2aP). ${ }^{18}$ Induction of elF2aP serves as an important 'checkpoint', under which general protein synthesis and cell proliferation are blocked, thus allowing cells to either recuperate from stress or be eliminated if the damage is beyond repair. ${ }^{19}$ elF2aP is mediated by a family of kinases consisting of the heme-regulated inhibitor (HRI), which is activated by heme deficiency to inhibit globin synthesis in erythroid cells; PKR, an interferon (IFN)-inducible protein with pro-inflammatory and antiviral properties, which is activated by binding to double-stranded (ds) RNA; the endoplasmic reticulum (ER)-resident protein kinase PERK/PEK, which is activated by the accumulation of misfolded proteins in the ER; and the general control non-derepressible-2 (GCN2), which is activated by accumulation of uncharged tRNAs caused by amino-acid starvation or nutrient deprivation. ${ }^{19,20}$ Despite the general shutdown of protein synthesis, certain mRNAs similar to those encoding the activating transcription factor 4 (ATF4)

\footnotetext{
${ }^{1}$ Lady Davis Institute for Medical Research, McGill University, Sir Mortimer B. Davis-Jewish General Hospital, Montreal, Quebec, Canada H3T 1E2; ${ }^{2}$ Department of Cancer Immunology, Chair of Medical Biotechnology, Poznan University of Medical Sciences, Poznan, Poland; ${ }^{3}$ Division of Experimental Medicine, Department of Medicine, Faculty of Medicine, McGill University, Montreal, Quebec, Canada H3A 1A3; ${ }^{4}$ Department of Biochemistry, Faculty of Medicine, McGill University, Montreal, Quebec, Canada H3G 1 Y6 and ${ }^{5}$ Department of Oncology, Faculty of Medicine, McGill University, Montreal, Quebec, Canada H2W 1S6

${ }^{*}$ Corresponding author: AE Koromilas, Lady Davis Institute for Medical Research, McGill University, Sir Mortimer B. Davis-Jewish General Hospital, Room 508, Montreal, Quebec, Canada H3T 1E2. Tel: +514 3408222 local 3697; Fax: +514 340 7576; E-mail: antonis.koromilas@mcgill.ca

Abbreviations: ATF, activating transcription factor; GCN, general control non-derepressible; ds RNA, double-stranded RNA; elF2 $\alpha$ P, elF2 $\alpha$ phosphorylated at S51; ER, endoplasmic reticulum; EGFR, epidermal growth factor receptor; $\mathrm{HRI}$, heme-regulated inhibitor; $\mathrm{H}_{2} \mathrm{O}_{2}$, hydrogen peroxide; IFN, interferon; mTORC, mammalian target of rapamycin complex; MEFs, mouse embryonic fibroblasts; IRS, insulin receptor substrate; KI, knock-in; PDK1, PI3K-dependent kinase 1; PAO, phenylarsine oxide; PEITC, $\beta$-phenylethyl isothiocyanate; PTEN, phosphatase and tensin homolog deleted in chromosome 10; PI3K, phosphatidylinositol 3-kinase; S6K, ribosomal S6 kinase; ROS, reactive oxygen species; TSC, tuberous sclerosis complex; WT, wild type

Received 28.7.14; revised 29.10.14; accepted 26.11.14; Edited by P Ekert
} 
and ATF5 in mammals and GCN4 in yeast are efficiently translated under conditions of increased elF $2 a \mathrm{P}$ through a mechanism that involves delayed translation re-initiation. ${ }^{21,22}$ Increased translation of ATF4 and ATF5 or GCN4 is required to increase the expression of genes that facilitate the adaptation of cells to stress. ${ }^{19}$

elF2 $a \mathrm{P}$ has an important role in the regulation of redox homeostasis and adaptation to oxidative stress in different species including humans, mice, worms and yeast. ${ }^{23-25}$ In metazoans, oxidative stress is closely linked to ER stress, given that accumulation of misfolded proteins in the ER leads to generation of ROS, which in turn can elicit the unfolded protein response (UPR) as a means to protect cells from stress. ${ }^{1}$ UPR activates the PERK-elF2 $a \mathrm{P}$ arm, which via the translational upregulation of ATF4 mediates the transcriptional induction of genes encoding antioxidant proteins. ${ }^{23}$ PERK can also exhibit an antioxidant effect independent of elF2aP through the phosphorylation and activation of transcription NF-E2-related factor 2 (Nrf2). ${ }^{26}$ The antioxidant function of elF2 $a \mathrm{P}$ also involves the attenuation of general protein synthesis, which decreases client protein load and prevents illegitimate disulfide bond formation in the ER leading to a sufficient amount of reducing equivalents to alleviate cells from oxidative stress. ${ }^{23}$ In addition, attenuation of protein synthesis by increased elF2aP prevents cells from ATP depletion and stimulation of mitochondrial oxidative phosphorylation and ROS production. ${ }^{27}$ Protein synthesis and ROS production are two processes that are tightly interdependent in stressed cells. That is, ATF4 contributes to restoration of protein synthesis following its inhibition by increased elF2 $a \mathrm{P}$ in response to ER stress. ${ }^{28,29}$ However, if restoration of protein synthesis occurs before the recovery of protein-folding capacity of the ER, increased ROS production by protein misfolding utilizes ATF4 to orchestrate a pro-apoptotic program that selectively eliminates stressed cells. ${ }^{28}$

We recently demonstrated that inactivation of the PERKelF2 $a \mathrm{P}$ arm in mouse as well as human primary fibroblasts is associated with increased ROS synthesis and induction of premature senescence. ${ }^{30}$ We noticed that unlike primary cells, which were intolerant to increased ROS levels, immortalized as well as tumor cells-deficient in elF $2 a \mathrm{P}$ were adapted to increased ROS production. ${ }^{30}$ This is consistent with other studies showing that tumor cells are tolerant to ROS up to a certain level, above which, they become sensitive to the antiproliferative effects of excessive oxidative stress. ${ }^{31,32}$ Cells engage several mechanisms to become tolerant to ROS some of which depend on Akt. ${ }^{11,13} \mathrm{~A}$ functional connection between Akt and elF2aP has been established by our group showing that Akt activation by ER stress depends on elF2aP. ${ }^{33,34} \mathrm{We}$ further showed that activated Akt in turn acts in a negative regulatory loop to decrease elF2 $a \mathrm{P}$ through the inactivation of PERK and GCN2. ${ }^{33,35}$ On the basis of these findings, we were interested to examine the roles of elF2aP and Akt in determining the sensitivity of immortalized and tumor cells to oxidative stress. Herein, we provide strong evidence that the cell fate function of elF2 $a \mathrm{P}$ is mediated by the regulation of Akt activity. Specifically, we found that elF2aP promotes Akt activation to facilitate cell survival under oxidative stress. Although impaired elF2 $a \mathrm{P}$ diminishes Akt activation, the remainder of activated Akt in elF2 $a \mathrm{P}$-deficient cells facilitates death in response to oxidative stress.

\section{Results}

elF2 $a \mathrm{P}$ promotes cell survival in response to oxidative stress. We observed that immortalized mouse embryonic fibroblasts (MEFs) expressing a serine 51 to alanine (S51A) mutant of elF2aP (herein referred to as knock-in (KI) cells) were highly susceptible to death by hydrogen peroxide $\left(\mathrm{H}_{2} \mathrm{O}_{2}\right)$ treatment compared with isogenic MEFs expressing wild-type (WT) elF2a (Figure 1a). Previous studies showed that among the elF2 $a$ kinases PERK and GCN2 promote survival, whereas PKR induces death in different cell types exposed to oxidative stress. ${ }^{23,36-39}$ On the other hand, HRI has had a more specialized role by promoting the survival of primary erythroid precursors subjected to oxidative stress. ${ }^{40}$ We obtained evidence that knockout (KO) of both PERK and GCN2 was required to render MEFs increasingly susceptible to death by $\mathrm{H}_{2} \mathrm{O}_{2}$ treatment compared with WT control cells (Figure 1b). In addition, whereas elF2 $a \mathrm{P}$ KI and PERK/GNC2 KO MEFs were increasingly susceptible to $\mathrm{H}_{2} \mathrm{O}_{2}$ treatment compared with their isogenic control counterparts, the amount of cell death caused by the loss of both PERK and GCN2 was higher than the amount of death caused by impaired elF2aP (Figures 1a and b). This phenomenon may be due to differences in the genetic background as previously shown by our group for MEFs subjected to stress by glucose deprivation. ${ }^{41}$ It is also possible that PERK and GNC2 promote cell survival under oxidative stress via elF $2 a \mathrm{P}$ dependent as well as -independent pathways as shown previously by the ability of PERK to mediate the activation of Nrf2. ${ }^{26}$ These data suggested that the pro-survival effects of increased elF2 $a \mathrm{P}$ in MEFs exposed to oxidative stress depend on the activation of PERK and GCN2.

Several studies have supported the notion that tumor cells are tolerant to intrinsic oxidative stress caused by increased ROS synthesis but become increasingly sensitive to extrinsic oxidative insults. ${ }^{32,42}$ To determine the role of elF $2 a \mathrm{P}$ in the sensitivity of tumor cells to oxidative stress, we employed human fibrosarcoma HT1080 cells and lung adenocarcinoma A549 cells, which were either proficient (WT) or deficient (KI cells) in elF2 $a \mathrm{P}^{30}$ Specifically, human tumor cells were made deficient in elF2 $a \mathrm{P}$ by infection with retroviruses expressing an $\mathrm{HA}$-tagged form of the phosphorylation-defective elF2aS51A followed by infection with lentiviruses targeting the $3^{\prime}$ UTR of endogenous elF $2 a .{ }^{30}$ We observed that elF $2 a \mathrm{P}$-deficient cells were more sensitive to death by $\mathrm{H}_{2} \mathrm{O}_{2}$ treatment than elF2 $a \mathrm{P}$ proficient cells (Figures $1 \mathrm{c}$ and $\mathrm{d}$ ). The increased sensitivity of the elF2aP-deficient tumor cells to oxidative stress was also observed when cells were treated with pro-oxidant drugs such as the cysteine oxidant phenylarsine oxide $(\mathrm{PAO})^{43,44}$ or $\beta$-phenylethyl isothiocyanate (PEITC), which disables the glutathione antioxidant system (Figures $2 a-c) .{ }^{13,45}$ elF2 $a \mathrm{P}$ deficient HT1080 cells were also increasingly susceptible to death by erastin, a pro-oxidant drug that preferentially kills tumor cells with activating ras mutations (Figure $2 \mathrm{~d}$ ). ${ }^{46}$ These data further supported the antioxidant and pro-survival 
a

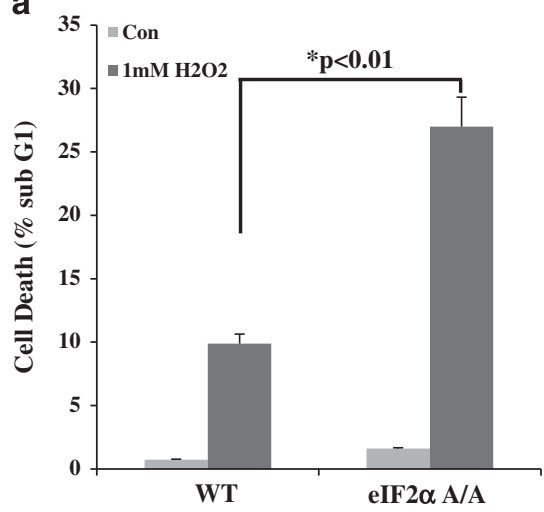

(KI)

C

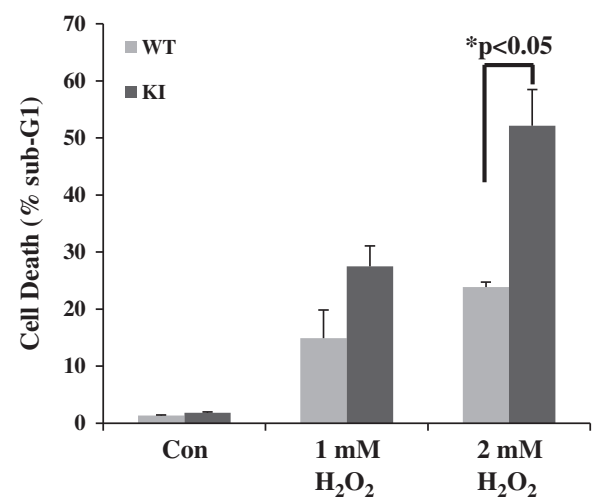

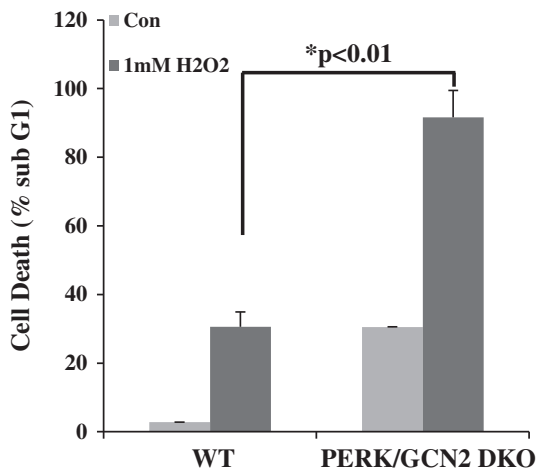

d

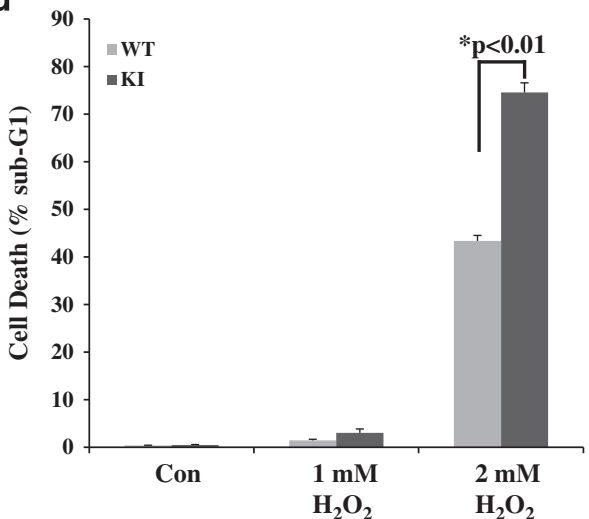

Figure 1 Deletion of PERK and GCN2 or impaired elF2 $\alpha$ P promotes cell death by oxidative stress. elF2 $\alpha$ P-deficient (KI) MEFs (a) or PERK and GCN2 double knock-out (DKO) MEFs together with their isogenic wild-type (WT) counterparts were treated with $1 \mathrm{mM} \mathrm{H}_{2} \mathrm{O}_{2}$ for $6 \mathrm{~h}$. Human fibrosarcoma HT1080 (c) or lung adenocarcinoma A549 cells (d) that were either proficient (WT) or deficient in elF2 $\alpha \mathrm{P}(\mathrm{KI})$ were treated with indicated concentrations of $\mathrm{H}_{2} \mathrm{O}_{2}$ for $8 \mathrm{~h}$. Cell death was assessed by the percentage of cells in sub- $\mathrm{G}_{1}$ population by propidium iodide staining and FACS analysis. Histograms represent the quantification from three independent experiments performed in triplicates. Error bars represent the S.E.

functions of elF2aP in tumor cells subjected to different forms of oxidative insults.

elF2aP deficiency compromises Akt activation in cells subjected to oxidative stress. An important mechanism utilized by cells to respond to oxidative insults involves the activation of Akt, which can promote cell survival or death. ${ }^{14}$ Previous work by our group showed that induction of elF2aP in response to ER stress leads to the activation of the PI3KAkt pathway as a means to protect cells from stress. ${ }^{34} \mathrm{We}$ found that $\mathrm{H}_{2} \mathrm{O}_{2}$ treatment resulted in a higher induction of Akt S473 phosphorylation in elF2aP-proficient than -deficient MEFs (Figure 3a). The ability of elF2aP to facilitate Akt S473 phosphorylation was further verified in elF2 $a \mathrm{P}$-proficient and -deficient HT1080 or A549 tumor cells exposed to either $\mathrm{H}_{2} \mathrm{O}_{2}$ or pro-oxidant drug PAO (Figures 3b-d). Because ATF4 is an important mediator of the antioxidant function of elF $2 a \mathrm{P}^{23}$ we examined whether ATF4 has a role in Akt regulation in response to oxidative stress. We found that ATF4 inactivation by either gene $\mathrm{KO}$ in MEFs or knockdown by the shRNA approach in HT1080 cells did not impair Akt S473 phosphorylation after $\mathrm{H}_{2} \mathrm{O}_{2}$ treatment (Figures $4 \mathrm{a}-\mathrm{d}$ ). These data indicated that Akt activation by elF2 $a \mathrm{P}$ in cells subjected to oxidative stress occurs via an ATF4-independent pathway.
Oxidative stress activates Akt via PI3K-dependent as well as -independent pathways. ${ }^{47,48}$ To determine the role of PI3K in this process, cells were treated with $\mathrm{H}_{2} \mathrm{O}_{2}$ in the presence of the specific PI3K inhibitor GDC-0941. We observed that GDC-0941 compromised Akt S473 phosphorylation in elF2 $a \mathrm{P}$-proficient and -deficient cells indicating that PI3K signaling has a primary role in Akt activation downstream of elF2aP (Figure 5a). A major mechanism of Akt regulation involves mTORC1, which upregulates a negative feedback loop from the ribosomal S6 kinases 1 and 2 (S6K1/2) to insulin receptor substrate (IRS1) resulting in PI3K inhibition. ${ }^{49-51}$ We observed that elF2aP deficiency in either immortalized MEFs or HT1080 and A549 tumor cells were associated with an increase in mTOR autophosphorylation at S2481 as well as mTOR phosphorylation at $\mathrm{S} 2448$ by $\mathrm{S} 6 \mathrm{~K}^{52-55}$ mTORC1 activation was further accompanied by an increase in S6K1 T389 phosphorylation and decreased Akt S473 phosphorylation making evident the presence of the negative regulatory loop downstream of mTORC1 (Figures 5b-d). To further substantiate this observation, cells were treated with the mTORC1 inhibitor rapamycin in order to eliminate the negative feedback regulation of Akt. We found that rapamycin treatment resulted in the induction of Akt S473 phosphorylation in both elF2 $a$ P-proficient and -deficient tumor cells at similar levels 
a

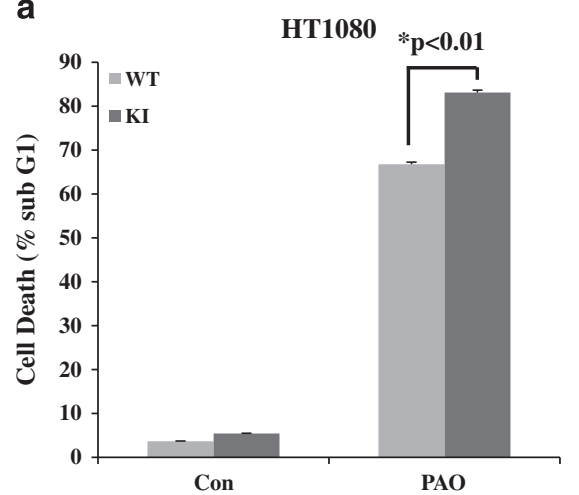

C

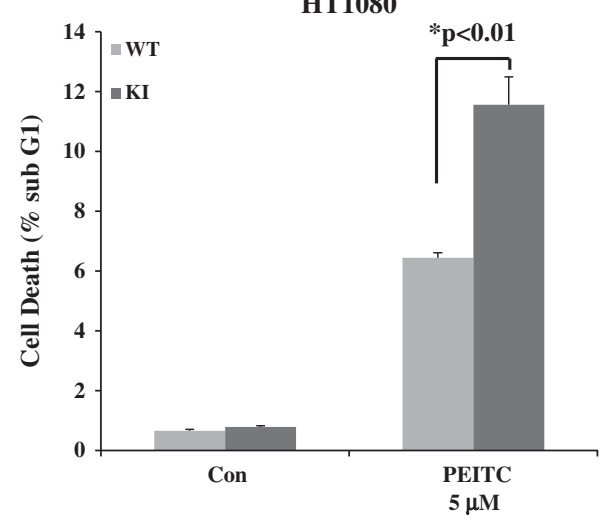

b

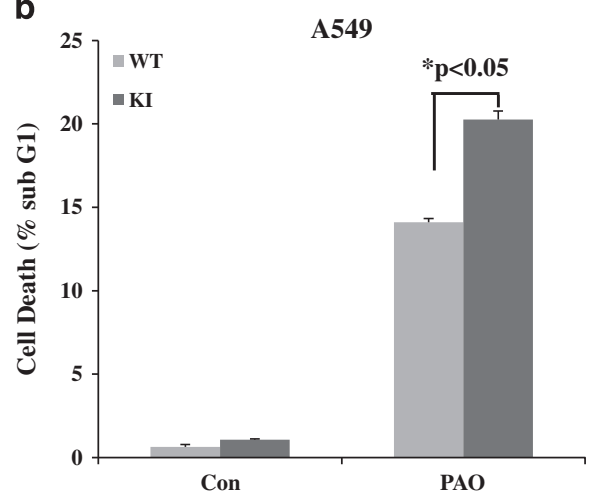

d

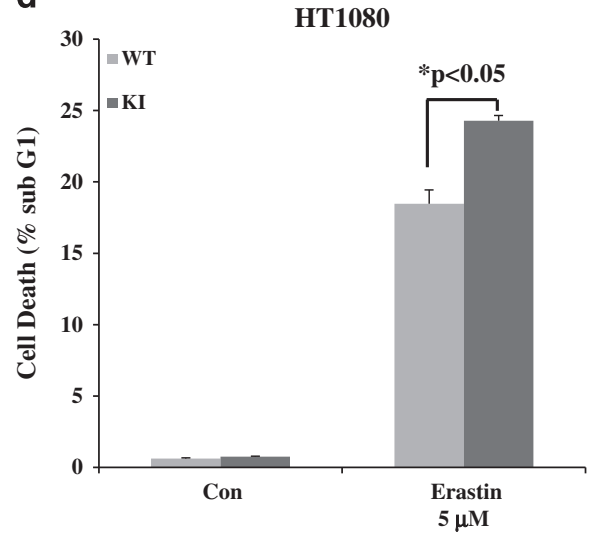

e

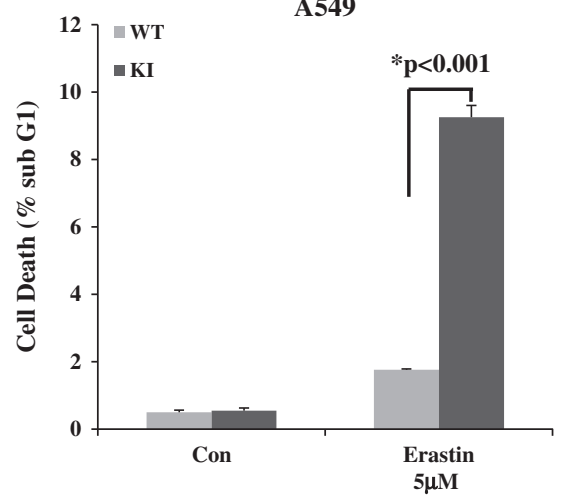

Figure 2 Impaired elF2 $\alpha \mathrm{P}$ sensitizes human tumor cells to death with pro-oxidant drugs. HT1080 and A549 cells that were either proficient (WT) or deficient in elF2 $\alpha \mathrm{P}$ (KI) were treated with $2 \mu \mathrm{M}$ of the pro-oxidant drug PAO (a and $\mathbf{b})$ for $6 \mathrm{~h}$ or with indicated concentrations of PEITC) (c) or erastin (d and e) for $24 \mathrm{~h}$. Histograms represent the percentage of cell death as indicated by the sub- $G_{1}$ population derived from two independent experiments performed in triplicates. Error bars represent the S.E.

(Figures $5 e$ and f). Restoration of Akt activity by rapamycin revealed the positive effect of elF2aP on PI3K-Akt signaling via the inactivation of $\mathrm{mTORC} 1$.

elF2 $a$ P determines the balance between cell survival and death by activated Akt under oxidative stress. To better understand the biological role of Akt, we employed HT1080 cells to impair mTORC2 activity by the expression of an shRNA, which was previously shown to cause an efficient downregulation of its Rictor component. ${ }^{56}$ We observed that Rictor impairment led to a substantial reduction of Akt S473 phosphorylation supporting the essential role of mTORC2 in
Akt activation by $\mathrm{S} 473$ phosphorylation (Figure 6a). ${ }^{56} \mathrm{We}$ also noticed that Rictor inactivation caused an increase in elF2 $a \mathrm{P}$ most likely due to Akt inactivation and inhibition of the feedback inhibitory effects of activated Akt on PERK and GCN2 as shown by our group (Figure 6a). ${ }^{35}$ We further observed that Rictor-deficient HT1080 cells were increasingly susceptible to death by $\mathrm{H}_{2} \mathrm{O}_{2}$ treatment suggesting that Akt activation by $\mathrm{S} 473$ phosphorylation has a prosurvival role in elF2aP-proficient cells exposed to oxidative stress (Figure 6b).

We next compared the effects of oxidative stress on elF2 $a \mathrm{P}$ proficient and -deficient cells treated with the pharmacological 
inhibitor Akti-1/2, which impairs the pleckstrin homology domain-dependent function of Akt 1 and 2 isoforms. ${ }^{57} \mathrm{We}$ observed that Akti-1/2 decreased Akt S473 phosphorylation in both elF2aP-proficient and -deficient cells after $\mathrm{H}_{2} \mathrm{O}_{2}$ treatment (Figure 6c). The lack of a complete inhibitory effect of the inhibitor on Akt S473 phosphorylation was most likely due to a

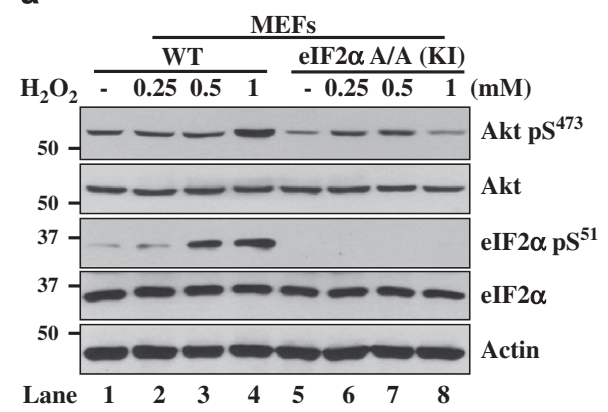

C

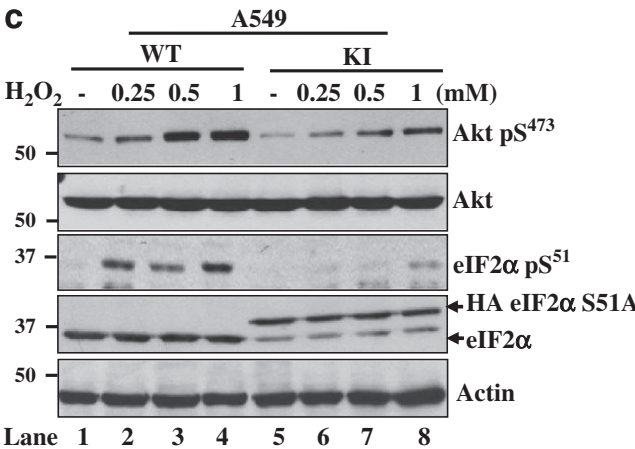

b

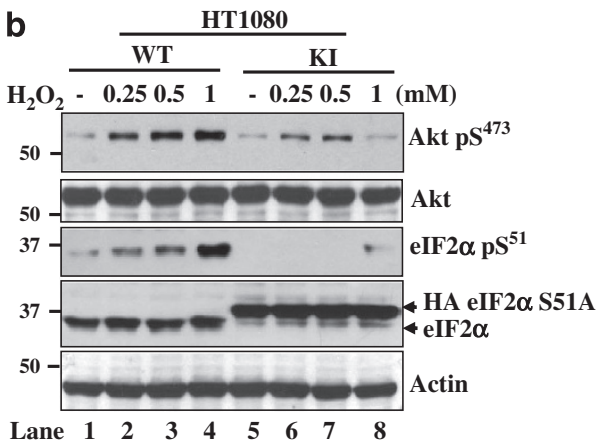

d

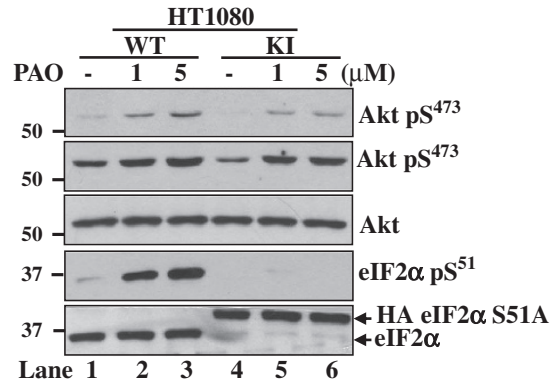

Figure 3 elF2 $\alpha$ P promotes Akt activation in response to oxidative stress. elF2 $\alpha \mathrm{P}$-proficient as well as -deficient immortalized MEFs (a), HT1080 cells (b and d) or A549 cells (c) were exposed to the indicated concentrations of either $\mathrm{H}_{2} \mathrm{O}_{2}(\mathrm{a}-\mathrm{c})$ for $2 \mathrm{~h}$ or PAO for $15 \mathrm{~min}$ (d). Protein extracts $(50 \mu \mathrm{g})$ were immunoblotted for the indicated proteins. The decreased migration of HA-elF2 $\alpha$ S51A in KI cells compared with endogenous elF2 $\alpha$ is indicated (b and c, lanes 5-8; d, lanes 4-6)

a

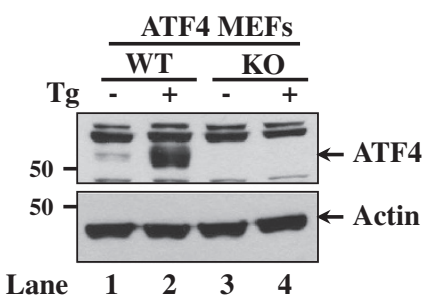

C

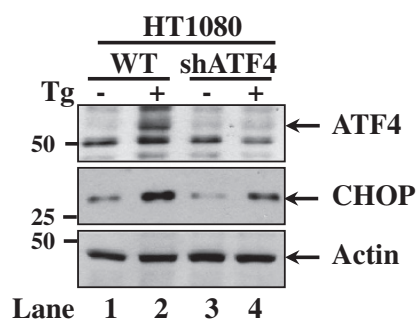

b

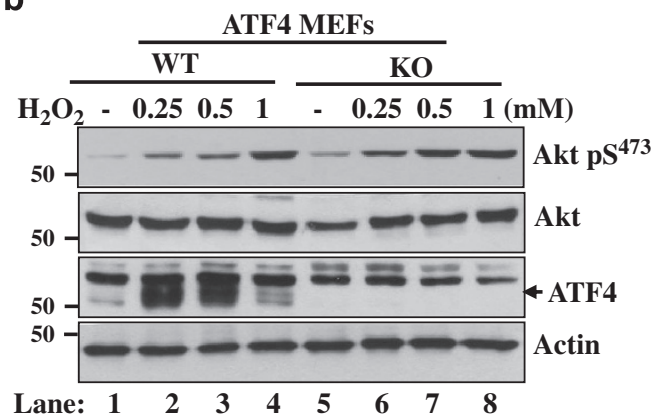

d

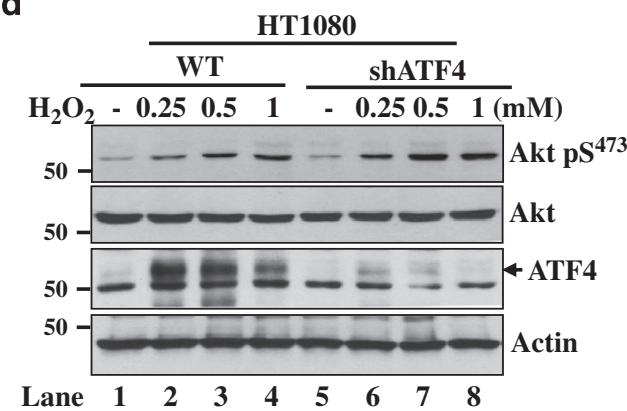

Figure 4 Akt activation by oxidative stress occurs independent of ATF4. MEFs (a and $\mathbf{b}$ ) or HT1080 cells, which were either proficient (WT) or deficient in ATF4 by gene KO (a and $\mathbf{b}$ ) or shRNA expression (c and d), were treated with $1 \mu \mathrm{M}$ thapsigargin $(\mathrm{Tg})$ for $4 \mathrm{~h}\left(\mathbf{a}\right.$ and $\mathbf{c}$ ) or exposed to indicated amounts of $\mathrm{H}_{2} \mathrm{O}_{2}$ for $2 \mathrm{~h}$. Protein extracts $(50 \mu \mathrm{g})$ were subjected to immunoblot analysis for the indicated proteins. Decreased levels of C/EBP homologous protein (CHOP) were used as a marker of ATF4 inactivation (c) 


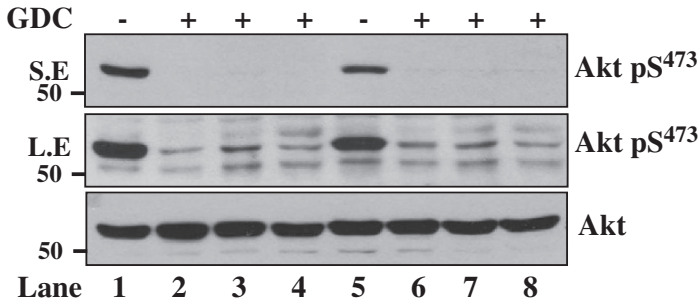

b

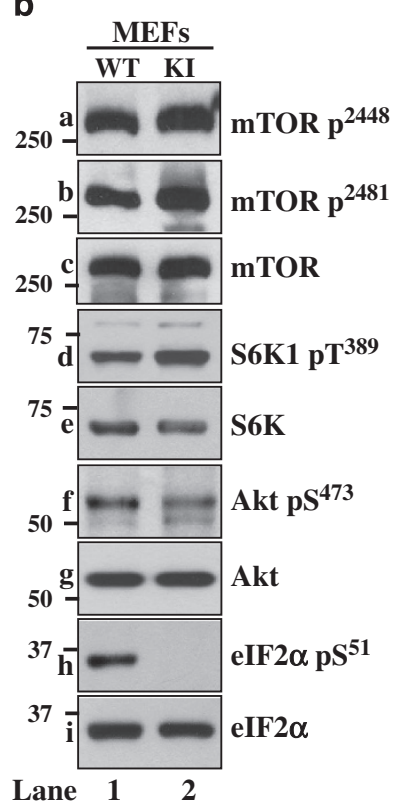

C

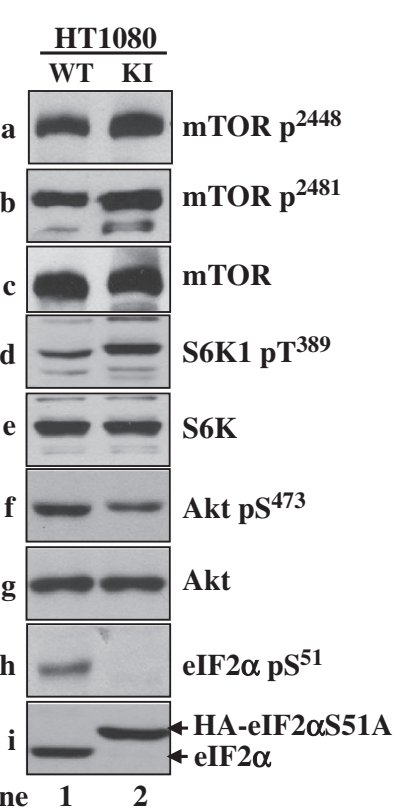

d

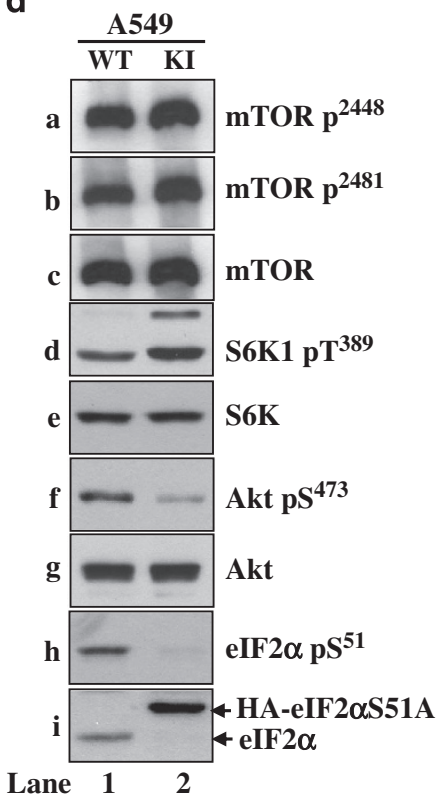

$\mathbf{e}$

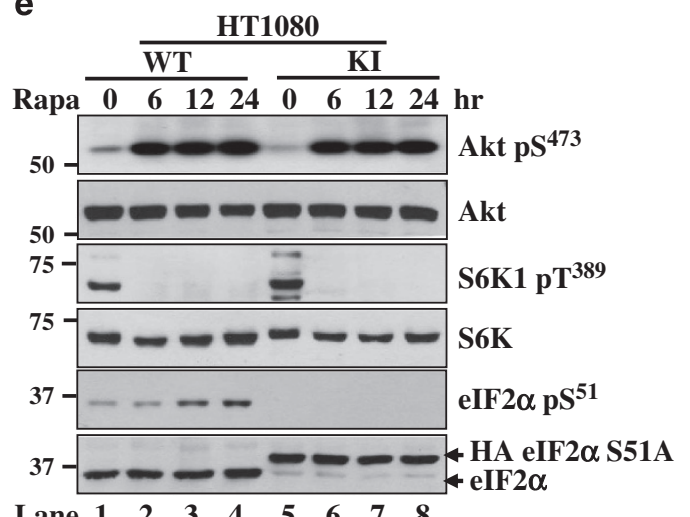

$\mathbf{f}$

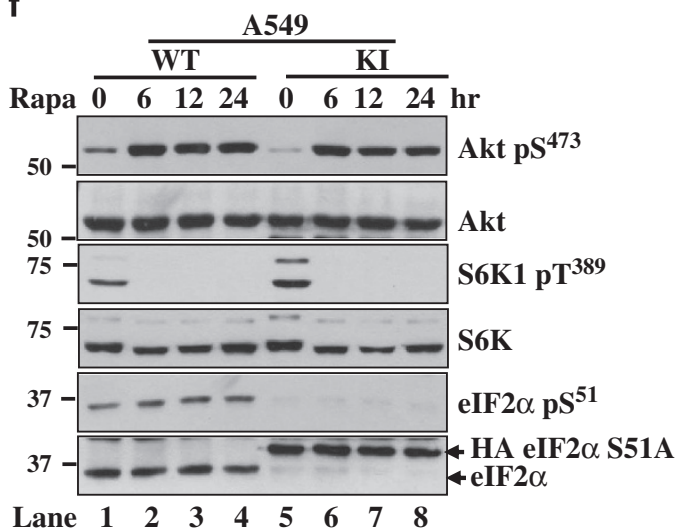

Figure 5 elF2 $\alpha$ P promotes Akt activation via mTORC1 inactivation. (a) Immunoblot analyses of $50-\mu \mathrm{g}$ protein extracts from elF2 $\alpha \mathrm{P}$-proficient (WT) or deficient (KI) HT1080 cells, which were pretreated with $5 \mu \mathrm{M}$ GDC-0941 for 30 min followed by treatments with the indicated concentrations of $\mathrm{H}_{2} \mathrm{O}_{2}$ for $2 \mathrm{~h}$. (b-d) Immunoblot analyses of 50 - $\mu \mathrm{g}$ protein extracts from MEFs (b), HT1080 cells (c) or A549 cells (d) that were either proficient (WT) or deficient in elF2 $\alpha \mathrm{P}$ (KI) in the absence of treatment. (d and e) Immunoblot analyses of 50- $\mu \mathrm{g}$ protein extracts from HT1080 WT and KI cells (e) or A549 WT and KI cells (f) before or after treatment with $20 \mathrm{ng} / \mathrm{ml}$ rapamycin for the indicated hours

efficient phosphorylation of Akt3 isoform (Figure 6c). We also noticed that Akti-1/2 treatment increased background elF2aP in elF2aP-proficient cells consistent with our interpretation that Akt inhibition relieves the negative regulation of elF2aP (Figure 6c, lane 3). ${ }^{35}$ When the biological effects of Akti-1/2 were tested, we found that Akt inhibition further enhanced the death of elF2aP-proficient HT1080 or A549 tumor cells in response to $\mathrm{H}_{2} \mathrm{O}_{2}$ (Figures $6 \mathrm{~d}$ and e). This result was in line with a pro-survival role of Akt in response to oxidative stress as also shown by Rictor inactivation (Figure 6b). Interestingly, we noticed that, in contrast to elF2aP-proficient cells, Akt inhibition prevented the death of elF2 $a \mathrm{P}$-deficient cells treated 

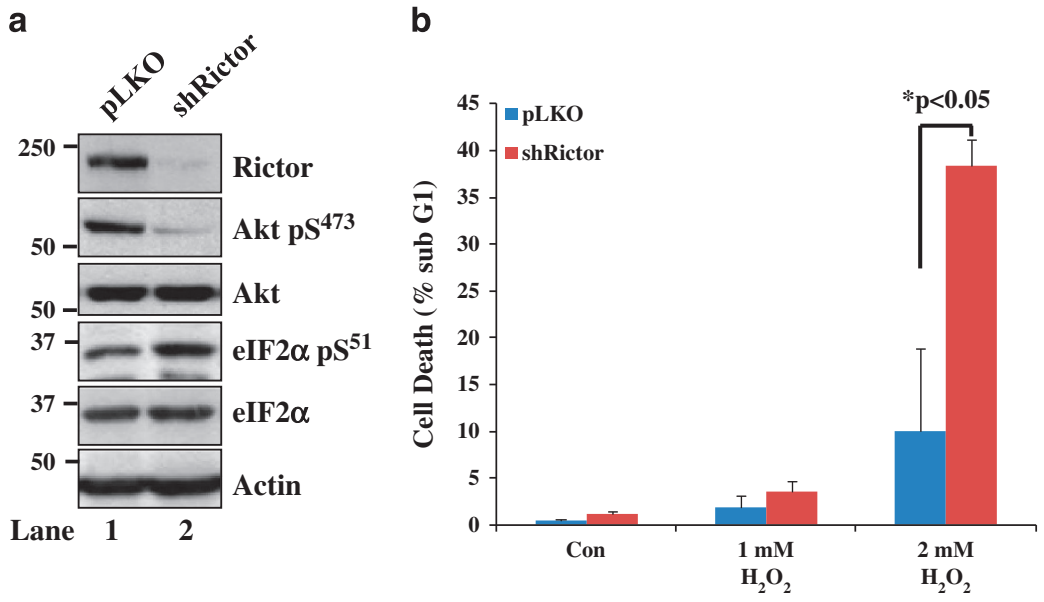

C

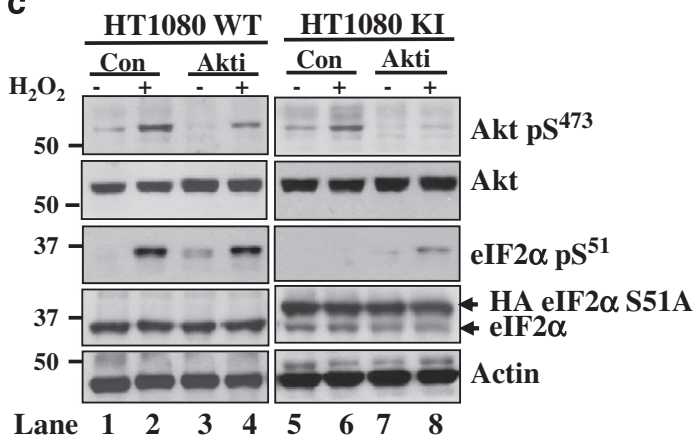

d

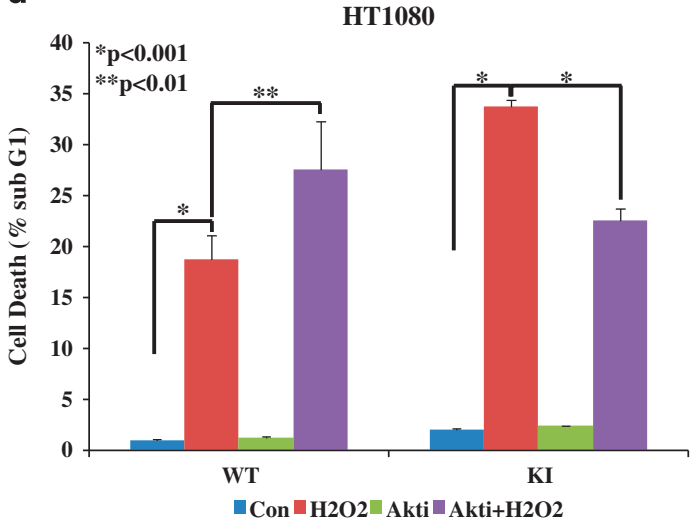

e

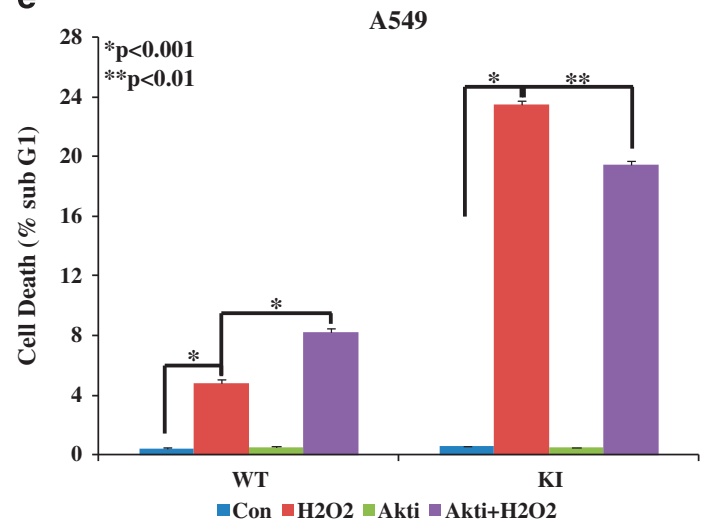

Figure 6 elF2 $\alpha$ P determines the cell fate effects of activated Akt in response to oxidative stress. (a) HT1080 cells were infected with either insert-less pLKO retroviruses or pLKO retroviruses expressing Rictor shRNA. After puromycin selection, protein extracts $(50 \mu \mathrm{g})$ were subjected to immunoblot analyses of the indicated proteins. (b) HT1080 cells that were either proficient (pLKO) or deficient in Rictor (shRictor) were subjected to treatment with the indicated concentrations of $\mathrm{H}_{2} \mathrm{O}_{2}$ for $6 \mathrm{~h}$. (c) HT1080 WT and KI cells were subjected to either single or combined treatments with $1 \mu \mathrm{M}$ Akt 1,2 (30 min pretreatment) followed by $1 \mathrm{mM} \mathrm{H}_{2} \mathrm{O}_{2}$ for $2 \mathrm{~h}$. Protein extracts $(50 \mu \mathrm{g}$ ) were used for immunoblot analyses of the indicated proteins. (d and e) elF2 $\alpha$ P-proficient (WT) or -deficient (KI) HT1080 cells (d) or A549 cells (e) were subjected to combination treatments with $1 \mu \mathrm{M}$ Akt 1,2 (30 min pretreatment) and/or $1 \mathrm{mM} \mathrm{H}_{2} \mathrm{O}_{2}$ for $6 \mathrm{~h}$. (b, $\mathbf{d}$ and $\mathbf{e}$ ) Cell death was assessed by the percentage of cells in sub- $\mathrm{G}_{1}$ population by propidium iodide staining and FACS analysis. Histograms represent the quantification from three independent experiments performed in triplicates. Error bars represent the S.E.

with $\mathrm{H}_{2} \mathrm{O}_{2}$ (Figures $6 \mathrm{~d}$ and e). These findings indicated that the lesser amount of activated Akt in elF2aP-deficient cells promotes death in response to oxidative stress.

Previous work showed that $\mathrm{mTORC} 1$ inhibition by rapamycin can promote Akt-mediated death in tumor cells subjected to oxidative therapies. ${ }^{13}$ Given that the regulation of Akt activity by elF2 $a \mathrm{P}$ depends on mTORC1 (Figure 5), we were interested to examine the effects of rapamycin on the sensitivity of elF2aP-proficient and -deficient cells to oxidative stress. We observed that treatment with $\mathrm{H}_{2} \mathrm{O}_{2}$ resulted in the downregulation of $\mathrm{mTORC} 1$ in both elF2 $a \mathrm{P}$-proficient and -deficient cells as shown by decreased S6K1 T389 phosphorylation (Figure 7a). We also noticed that mTORC1 inhibition by rapamycin restored the differences in Akt $\mathrm{S} 473$ phosphorylation in elF2aP-proficient and -deficient cells treated with $\mathrm{H}_{2} \mathrm{O}_{2}$ (Figure 7a). These data indicated that mTORC1 inactivation 
a

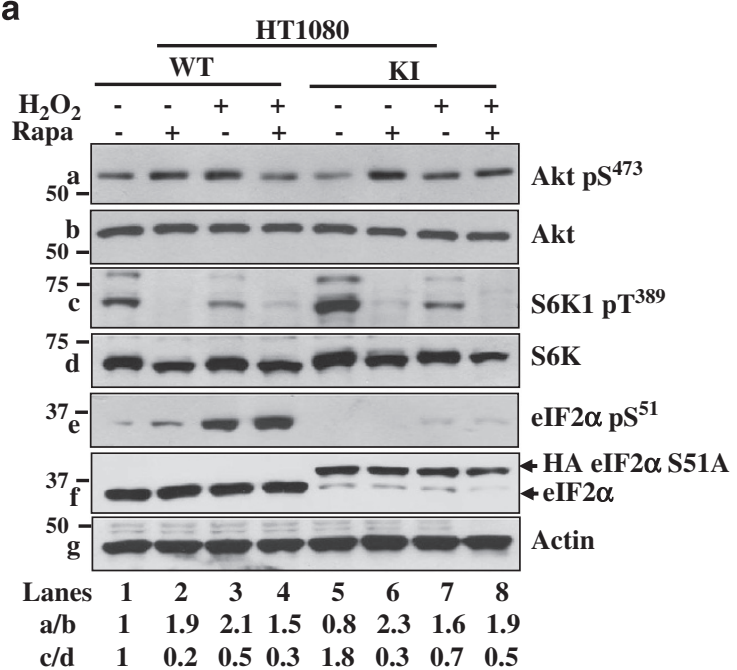

b

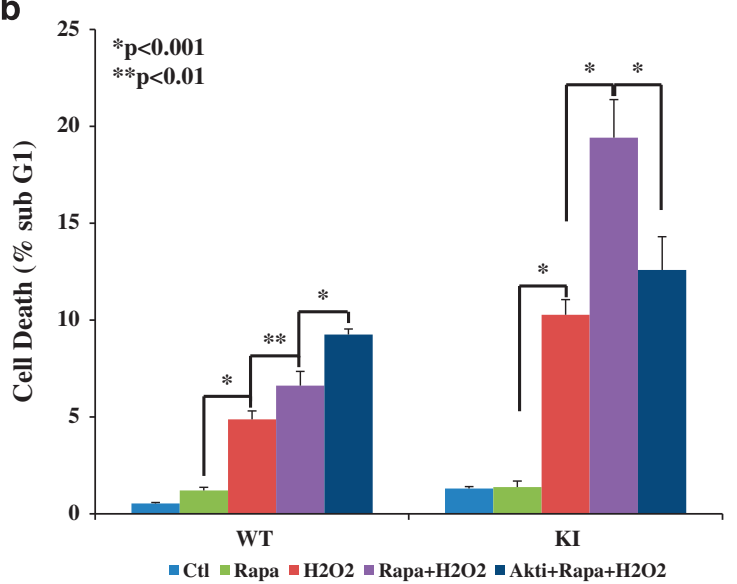

Figure 7 Induction of Akt-mediated death in rapamycin-treated elF2 $\alpha$ P-deficient cells subjected to oxidative stress. (a) elF2 $\alpha$ P-proficient (WT) and -deficient cells (KI) were subjected to either single or combined treatments with $0.5 \mathrm{mM} \mathrm{H}_{2} \mathrm{O}_{2}$ and/or $20 \mathrm{nM}$ rapamycin for up to $2 \mathrm{~h}$. Protein extracts $(50 \mu \mathrm{g})$ were subjected to immunoblot analyses for the indicated proteins. (b) HT1080 WT and KI cells were subjected to either single or combined treatments with $1 \mu \mathrm{M}$ Akt 1,2 and/or $0.5 \mathrm{mM} \mathrm{H}_{2} \mathrm{O}_{2}$ and/or $20 \mathrm{nM}$ rapamycin for $24 \mathrm{~h}$. Cell death was assessed by the percentage of cells in sub$\mathrm{G}_{1}$ population by propidium iodide staining and FACS analysis. Histograms represent the quantification from three independent experiments performed in triplicates. Error bars represent the S.E.

contributes to elF2aP-mediated Akt activation in cells subjected to oxidative stress (Figure 7a). Concerning the biological effects, rapamycin treatment substantially increased death in both elF2aP-proficient and -deficient cells with the latter cells exhibiting a stronger effect (Figure 7b). These data implied a pro-survival role of mTORC1 in cells subjected to oxidative stress, which was more evident for elF2aP-deficient cells (Figure 7b). Because rapamycin induces Akt activity, we examined the role of Akt by inhibiting its activity in cells subjected to treatments with rapamycin and $\mathrm{H}_{2} \mathrm{O}_{2}$. We found that Akt inhibition by Akti-1,2 treatment further increased the death of elF2aP-proficient cells but substantially decreased the death of elF2aP-deficient cells (Figure 7b). Taken together, these data strongly suggested that

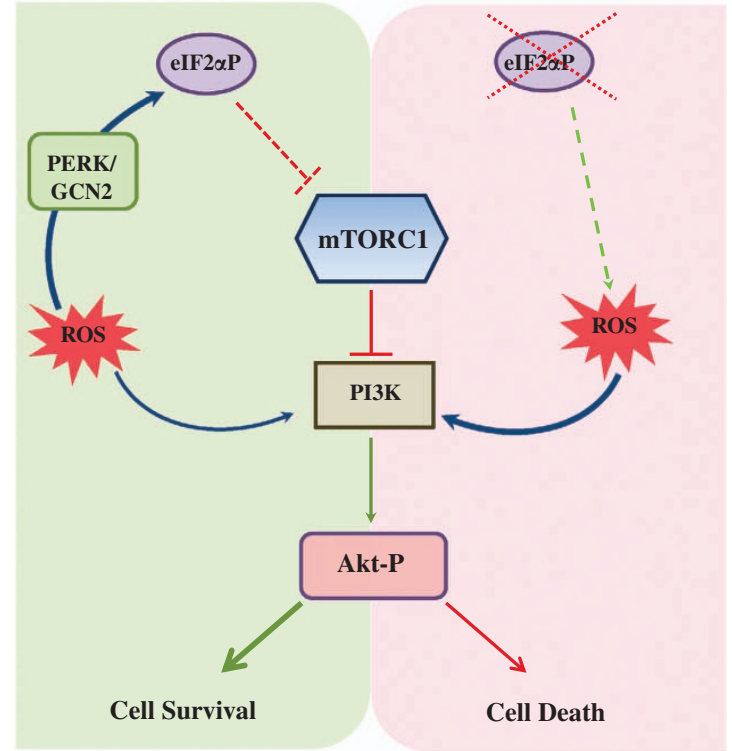

Figure 8 Schematic representation of the functional interactions between elF2 $\alpha \mathrm{P}$ and Akt in response to oxidative stress. Oxidative stress induces elF2 $\alpha \mathrm{P}$ and Akt activation through PERK-GCN2 and PI3K, respectively. (Left panel) In cells that are proficient in elF2 $\alpha \mathrm{P}$, increased elF2 $\alpha \mathrm{P}$ decreases mTORC1, which in turn relieves the feedback inhibition of PI3K signaling leading to increased Akt activity and cell survival. (Right panel) In cells that are deficient in elF2 $\alpha$ P, mTORC1 activity is upregulated, which in turn diminishes Akt activation through the negative regulation of PI3K signaling. The remainder of activated Akt in these cells promotes cell death in response to oxidative stress. Loss of elF2 $\alpha \mathrm{P}$ can also lead to increased ROS production, ${ }^{30}$ which may further sensitize cells to extrinsic oxidative stress

(i) mTORC1 conveys a pro-survival function in cells under oxidative stress, which is stronger in elF2aP-deficient than -proficient cells, and (ii) mTORC1 inhibition by rapamycin induces Akt activity to increase the survival of elF2aP-proficient cells and promote the death of elF2aPdeficient cells.

\section{Discussion}

Our study uncovers an important role of elF2aP in the regulation of cell fate in response to oxidative stress. Our data support a model in which immortalized as well as tumor cells under oxidative stress induces elF2aP through the activation of PERK and GCN2 (Figure 8, left panel). Increased elF2aP mediates the downregulation of mTORC1 activity, which in turn alleviates the negative regulation of the PI3K-Akt pathway through a previously well-characterized feedback mechanism involving S6K-IRS1 ${ }^{49-51}$ Decreased mTORC1 activity accounts, at least in part, for the induction of Akt activity in elF2aP-proficient cells under oxidative stress as shown in rapamycin-treated cells (Figure 5). In addition, Akt activation in elF2aP-proficient cells promotes survival inasmuch as its inactivation by genetic or pharmacological means enhances death in response to oxidative stress (Figure 6). On the other hand, impaired elF2aP sensitizes immortalized as well as tumor cells to death after treatment with different forms of pro-oxidant agents (Figure 8, right panel). This is because impaired elF2aP increases mTORC1 activity, which in turn decreases Akt activity owing to upregulation of the feedback 
loop leading to PI3K inactivation. Impaired elF2aP may further contribute to oxidative stress by upregulating intrinsic ROS synthesis as recently shown by our group. ${ }^{30}$ Despite the downregulation of Akt activity in elF2aP-deficient cells, the remainder of activated Akt promotes cell death in response to oxidative stress (Figure 7). Thus, elF2aP may be an important determinant of the cell fate decisions of activated Akt in cells subjected to oxidative insults.

Other studies have also provided evidence for a functional cross-talk between elF2 $a \mathrm{P}$ and mTORC1 pathways under different conditions of stress. Specifically, activation of GCN2ATF4 arm in response to amino-acid deprivation was shown to increase the expression of pyruvate kinase (PKM2), which in turn upregulated mTORC1 activity. ${ }^{58}$ In addition, cells exposed to chronic ER stress were found to induce the PERK-elF2 $a$ P-ATF4 arm, which together with mTORC1 was involved in the recovery of mRNA translation under stress. ${ }^{59}$ Furthermore, GCN2-deficient mice displayed enhanced mTORC1 activity and increased sensitivity to oxidative stress caused by asparaginase treatment. ${ }^{60}$ Our data support the notion that the biological function of $\operatorname{mTORC} 1$ activation in response to oxidative stress conveys a pro-survival function. This is supported by the induction of death in both elF2 $a \mathrm{P}$ proficient and -deficient cells after mTORC1 inhibition by rapamycin (Figure $7 \mathrm{~b}$ ). However, the pro-death effects of rapamycin were affected by Akt and elF2aP inasmuch as Akt inactivation further promoted the killing effects of rapamycin in elF2 $a$ P-proficient cells but rescued elF2 $a$ P-deficient cells from oxidative death (Figure 7b). Our data are in agreement with previous studies indicating that elF2 $a \mathrm{P}$ status can determine mTORC1 activation in cells subjected to oxidative stress. Specifically, tethering of mTORC1 to stress granules was shown to prevent $\mathrm{mTORC} 1$ hyperactivation in cells subjected to different forms of oxidative stress. ${ }^{61}$ This may be a mechanism by which elF2 $a \mathrm{P}$ contains mTORC1 activity, given that stress granule formation by oxidative stress depends on elF2 $a \mathrm{P}{ }^{61,62}$ Furthermore, mTORC1 hyperactivation by oxidative stress can have a pro-apoptotic role in cells deficient in tuberous sclerosis complex (TSC). ${ }^{61,63}$ Given that Akt activity is impaired in TSC-mutant cells, Akt inactivation may be a mechanism by which mTORC1 becomes pro-apoptotic in cells exposed to oxidative stress.

Our data show that induction of elF2aP promotes Akt activation and facilitates cell survival in response to oxidative stress. The data support previous work from our group showing that induction of elF2 $a \mathrm{P}$ in human tumor cells expressing a conditionally active form of PKR resulted in Akt activation as a means to protect cells from death. ${ }^{33,34}$ In addition, PERK activation and increased eIF $2 a \mathrm{P}$ by ER stress resulted in the induction of the PI3K-Akt pathway to promote cell survival. ${ }^{33,34}$ However, it is important to emphasize that, in addition to its ability to activate Akt, elF2 $a \mathrm{P}$ is also under regulation by activated Akt. Specifically, we recently demonstrated that Akt inactivation by genetic or pharmacological means induces elF2 $a \mathrm{P}$ via the activation of PERK and GCN2. ${ }^{33,35}$ This is because PERK and GCN2 are inhibited by Akt-mediated phosphorylation and as such, each elF2a kinase regains full activity under conditions of Akt inactivation. ${ }^{33,35}$ This process may account for increased elF2 $a \mathrm{P}$ in tumor cells with impaired Akt S473 phosphorylation as indicated by mTORC2 disruption or pharmacological inhibition of Akt (Figures 6a and c). To date, our work supports a model in which elF2aP and Akt are intertwined in an autoregulatory loop with implications in cell survival under stress. ${ }^{33}$ Specifically, increased elF2aP facilitates the induction of PI3K-Akt signaling, which in turn through the sustained activation of Akt reduces PERK and GCN2 activities as a means to balance elF $2 a \mathrm{P}^{33}$ Cells respond to the inhibition of the PI3K-Akt pathway by upregulating elF2aP owing to Akt inactivation and subsequent activation of PERK and GCN2. ${ }^{33}$ In this model, both elF2 $a \mathrm{P}$ and PI3K-Akt pathways have prosurvival roles with one to substitute for the other under conditions of stress. ${ }^{33}$

Our work may have important implications in antitumor treatments. Specifically, treatment with pro-oxidant drugs is considered an efficient strategy to kill cancer cells that exhibit increased tolerance to ROS. ${ }^{32,64,65}$ Because the PI3K-Akt pathway is upregulated in the majority of human cancers, exploiting the pro-death effects of Akt is considered to be an effective strategy in tumor treatment with pro-oxidant drugs. ${ }^{13}$ The pro-death properties of Akt were shown to be mediated by its ability to induce ROS production by increasing oxygen consumption, thereby stimulating oxidative metabolism as well as by repressing the expression of antioxidant genes thorough the inactivation of FoxO transcription factors. ${ }^{13,14}$ Herein, we provide strong evidence that elF2 $a \mathrm{P}$ is an important factor in determining the consequence of Akt activation in cells exposed to oxidative stress. Our data show that impaired elF $2 a \mathrm{P}$ is sufficient to disarm the pro-survival and promote the killing effects of Akt on tumor cells under oxidative stress. Given that inhibitors of the elF2 $a \mathrm{P}$ pathway have started to emerge, ${ }^{66-68}$ pharmacological inhibition of elF2 $a \mathrm{P}$ may hold a promise for the development of strategies that enhance the antitumor effects of pro-oxidant drugs on tumors with hyperactivated Akt.

\section{Materials and Methods}

Cell culture and treatments. The elF2 $\alpha \mathrm{P}$-proficient or -deficient MEFs, HT1080 and A549 tumor cells were generated as described previously. ${ }^{30}$ ATF4 KO MEFs as well as PERK/GCN2 KO MEFs were previously described. ${ }^{41,59}$ Cells were cultured in Dulbecco modified Eagle medium (Wisent, St-Bruno, QC, Canada) supplemented with 10\% fetal bovine serum (FBS; Gibco, Burlington, ON, Canada), antibiotics (100 U/ml of penicillin-streptomycin; Gibco) and $2.5 \mu \mathrm{g} / \mathrm{ml}$ of puromycin (Sigma, Oakville, ON, Canada). The shRNA-mediated KO of ATF4 in HT1080 cells was carried out based on previously reported protocol. ${ }^{69}$ Lentiviral shRNA targeting ATF4 (TRCN0000013573) was obtained from the RNAi Consortium (TRC) arrayed human genome-wide shRNA collection (Sigma). shRNA-mediated $\mathrm{KO}$ of Rictor was performed as described previously. ${ }^{56} \mathrm{H}_{2} \mathrm{O}_{2}$ was purchased from Bioshop, Canada; GDC-0941 was obtained from Selleckchem, USA; thapsigargin, rapamycin, Akt1,2 inhibitor, PAO, PEITC and erastin were obtained from Sigma.

Flow cytometry analysis. Cells were subjected to propidium iodide staining and FACScan analysis based on a previously described protocol..$^{35}$ FACS was performed with BD FACScalibur and the data were analyzed using the FlowJo software (Tree Star Inc., Ashland, OR, USA).

Western blot analysis. Protein extraction and immunoblotting were performed as described. ${ }^{30}$ The antibodies used were as follows: rabbit monoclonal against phosphorylated elF2 $\alpha$ at S51 (Novus Biologicals, Oakville, ON, Canada), mouse monoclonal against elF2 $\alpha$, rabbit monoclonal against phosphorylated Akt at S473, rabbit polyclonal against Akt, rabbit monoclonal against phosphorylated mTOR at S2448 and mTOR, S6K phosphorylated at T389 and S6K, rabbit 
polyclonal against phosphorylated mTOR at S2481, rabbit polyclonal against CHOP and Rictor were from Cell Signaling Technology (Beverly, MA, USA), rabbit polyclonal against ATF4 (Proteintech, Chicago, IL, USA) and mouse monoclonal antibody against actin (Clone C4, ICN Biomedicals Inc., Irvine, CA, USA). All antibodies were used at a final concentration of $0.1-1 \mu \mathrm{g} / \mathrm{ml}$. Following incubation with the indicated primary antibodies and washes, membranes were probed with anti-mouse or anti-rabbit IgG antibodies conjugated to horseradish peroxidise (Mandel Scientific, Guelph, ON, Canada). Proteins were visualized with the enhanced chemiluminescence reagent (Thermo Scientific, Waltham, MA, USA) detection system according to the manufacturer's instructions. Quantification of bands in linear range of exposure was performed by densitometry using the Scion image software (Frederick, MD, USA).

Statistical analysis. Error bars represent S.D. as indicated and significance in differences between arrays of data tested was determined using two-tailed Student t-test (Microsoft Excel).

\section{Conflict of Interest}

The authors declare no conflict of interest.

Acknowledgements. We thank members of the Molecular Oncology Group for helpful comments. The work was supported by funds from the Canadian Cancer Society Research Institute (CCSRI no. 700886) and the Canadian Institutes of Health Research (CIHR MOP no. 38160) to AEK as well as a CIHR grant MOP no. 130540 to SH. SH is a recipient of a Canada Research Chair (CRC) in Functional Genomics, whereas AIP is a CIHR-funded McGill Chemical Biology Postdoctoral Fellowship Award.

1. Holmstrom KM, Finkel T. Cellular mechanisms and physiological consequences of redoxdependent signalling. Nat Rev Mol Cell Biol 2014; 15: 411-421.

2. Leslie NR. The redox regulation of PI 3-kinase-dependent signaling. Antioxid Redox Signal 2006; 8: 1765-1774.

3. Liu P, Cheng H, Roberts TM, Zhao JJ. Targeting the phosphoinositide 3-kinase pathway in cancer. Nat Rev Drug Discov 2009; 8: 627-644.

4. Wang X, McCullough KD, Franke TF, Holbrook NJ. Epidermal growth factor receptordependent Akt activation by oxidative stress enhances cell survival. J Biol Chem 2000; 275: 14624-14631.

5. Picone P, Giacomazza D, Vetri V, Carrotta R, Militello V, San Biagio PL et al. Insulinactivated Akt rescues Abeta oxidative stress-induced cell death by orchestrating molecular trafficking. Aging Cell 2011; 10: 832-843.

6. Zheng L, Ishii Y, Tokunaga A, Hamashima T, Shen J, Zhao QL et al. Neuroprotective effects of PDGF against oxidative stress and the signaling pathway involved. J Neurosci Res 2010; 88: 1273-1284.

7. Muders MH, Zhang H, Wang E, Tindall DJ, Datta K. Vascular endothelial growth factor-C protects prostate cancer cells from oxidative stress by the activation of mammalian target of rapamycin complex-2 and AKT-1. Cancer Res 2009; 69: 6042-6048.

8. Tapodi A, Debreceni B, Hanto K, Bognar Z, Wittmann I, Gallyas F Jr. et al. Pivotal role of Akt activation in mitochondrial protection and cell survival by poly(ADP-ribose)polymerase-1 inhibition in oxidative stress. J Biol Chem 2005; 280: 35767-35775.

9. Taylor JM, Ali U, lannello RC, Hertzog P, Crack PJ. Diminished Akt phosphorylation in neurons lacking glutathione peroxidase-1 (Gpx1) leads to increased susceptibility to oxidative stress-induced cell death. J Neurochem 2005; 92: 283-293.

10. Wang JF, Zhang X, Groopman JE. Activation of vascular endothelial growth factor receptor-3 and its downstream signaling promote cell survival under oxidative stress. J Biol Chem 2004; 279: 27088-27097.

11. Ikeyama S, Kokkonen G, Shack S, Wang XT, Holbrook NJ. Loss in oxidative stress tolerance with aging linked to reduced extracellular signal-regulated kinase and Akt kinase activities. FASEB J 2002; 16: 114-116.

12. Ding J, Takano T, Gao S, Han W, Noda C, Yanagi S et al. Syk is required for the activation of Akt survival pathway in B cells exposed to oxidative stress. $J$ Biol Chem 2000; 275: 30873-30877.

13. Nogueira V, Park Y, Chen CC, Xu PZ, Chen ML, Tonic I et al. Akt determines replicative senescence and oxidative or oncogenic premature senescence and sensitizes cells to oxidative apoptosis. Cancer Cell 2008; 14: 458-470.

14. Nogueira V, Hay N. Molecular pathways: reactive oxygen species homeostasis in cancer cells and implications for cancer therapy. Clin Cancer Res 2013; 19: 4309-4314.

15. Los M, Maddika S, Erb B, Schulze-Osthoff K. Switching Akt: from survival signaling to deadly response. Bioessays 2009; 31: 492-495.

16. Astle MV, Hannan KM, Ng PY, Lee RS, George AJ, Hsu AK et al. AKT induces senescence in human cells via mTORC1 and p53 in the absence of DNA damage: implications for targeting mTOR during malignancy. Oncogene 2012; 31: 1949-1962.
17. Miyauchi $\mathrm{H}$, Minamino T, Tateno K, Kunieda $\mathrm{T}$, Toko H, Komuro I. Akt negatively regulates the in vitro lifespan of human endothelial cells via a p53/p21-dependent pathway. EMBO J 2004; 23: 212-220.

18. Holcik M, Sonenberg N. Translational control in stress and apoptosis. Nat Rev Mol Cell Biol 2005; 6: 318-327.

19. Koromilas AE. Roles of the translation initiation factor elF2 $\alpha$ serine 51 phosphorylation in cancer formation and treatment. Biochim Biophys Acta 2014; e-pub ahead of print 11 December 2014; doi:10.1016/..bbagrm.2014.12.007.

20. Chen JJ. Regulation of protein synthesis by the heme-regulated elF2alpha kinase: relevance to anemias. Blood 2007; 109: 2693-2699.

21. Dever TE, Feng L, Wek RC, Cigan AM, Donahue TF, Hinnebusch AG. Phosphorylation of initiation factor 2 alpha by protein kinase GCN2 mediates gene-specific translational control of GCN4 in yeast. Cell 1992; 68: 585-596.

22. Sonenberg N, Hinnebusch AG. Regulation of translation initiation in eukaryotes: mechanisms and biological targets. Cell 2009; 136: 731-745.

23. Harding HP, Zhang Y, Zeng H, Novoa I, Lu PD, Calfon M et al. An integrated stress response regulates amino acid metabolism and resistance to oxidative stress. Mol Cell 2003; 11: 619-633.

24. Nemoto N, Udagawa T, Ohira T, Jiang L, Hirota K, Wikinson CR et al. The roles of stressactivated Sty1 and Gcn2 kinases and of the protooncoprotein homologue Int6/elF3e in responses to endogenous oxidative stress during histidine starvation. J Mol Biol 2010; 404: 183-201.

25. Zhan K, Vattem KM, Bauer BN, Dever TE, Chen JJ, Wek RC. Phosphorylation of eukaryotic initiation factor 2 by heme-regulated inhibitor kinase-related protein kinases in Schizosaccharomyces pombe is important for fesistance to environmental stresses. Mol Cell Biol 2002; 22: 7134-7146.

26. Cullinan SB, Diehl JA. Coordination of ER and oxidative stress signaling: the PERK/Nrf2 signaling pathway. Int J Biochem Cell Biol 2006; 38: 317-332.

27. Feissner RF, Skalska J, Gaum WE, Sheu SS. Crosstalk signaling between mitochondrial Ca2+ and ROS. Front Biosci 2009; 14: 1197-1218.

28. Han J, Back SH, Hur J, Lin YH, Gildersleeve R, Shan J et al. ER-stress-induced transcriptional regulation increases protein synthesis leading to cell death. Nat Cell Biol 2013; 15: 481-490.

29. Krokowski D, Han J, Saikia M, Majumder M, Yuan CL, Guan BJ et al. A self-defeating anabolic program leads to beta-cell apoptosis in endoplasmic reticulum stress-induced diabetes via regulation of amino acid flux. J Biol Chem 2013; 288: 17202-17213.

30. Rajesh K, Papadakis Al, Kazimierczak U, Peidis P, Wang S, Ferbeyre G et al. elF2alpha phosphorylation bypasses premature senescence caused by oxidative stress and prooxidant antitumor therapies. Aging (Albany NY) 2013; 5: 884-901.

31. Lu T, Finkel T. Free radicals and senescence. Exp Cell Res 2008; 314: 1918-1922.

32. Trachootham D, Alexandre J, Huang P. Targeting cancer cells by ROS-mediated mechanisms: a radical therapeutic approach? Nat Rev Drug Discov 2009; 8: 579-591.

33. Koromilas AE, Mounir Z. Control of oncogenesis by elF2alpha phosphorylation: implications in PTEN and PI3K-Akt signaling and tumor treatment. Future Oncol 2013; 9: 1005-1015.

34. Kazemi S, Mounir Z, Baltzis D, Raven JF, Wang S, Krishnamoorthy JL et al. A novel function of elF2alpha kinases as inducers of the phosphoinositide-3 kinase signaling pathway. Mol Biol Cell 2007; 18: 3635-3644.

35. Mounir Z, Krishnamoorthy JL, Wang S, Papadopoulou B, Campbell S, Muller WJ et al. Akt determines cell fate through inhibition of the PERK-elF2\{alpha\} phosphorylation pathway. Sci Signal 2011; 4: ra62.

36. Back SH, Scheuner D, Han J, Song B, Ribick M, Wang J et al. Translation attenuation through elF2alpha phosphorylation prevents oxidative stress and maintains the differentiated state in beta cells. Cell Metab 2009; 10: 13-26.

37. Baker BM, Nargund AM, Sun T, Haynes CM. Protective coupling of mitochondrial function and protein synthesis via the elF2alpha kinase GCN-2. PLoS Genet 2012; 8: e1002760.

38. Lozon TI, Eastman AJ, Matute-Bello G, Chen P, Hallstrand TS, Altemeier WA. PKR-dependent CHOP induction limits hyperoxia-induced lung injury. Am J Physiol Lung Cell Mol Physiol 2011; 300: L422-L429.

39. Pyo CW, Lee SH, Choi SY. Oxidative stress induces PKR-dependent apoptosis via IFN-gamma activation signaling in Jurkat T cells. Biochem Biophys Res Commun 2008; 377 : 1001-1006.

40. Chen JJ. Translational control by heme-regulated elF2alpha kinase during erythropoiesis. Curr Opin Hematol 2014; 21: 172-178.

41. Muaddi H, Majumder M, Peidis P, Papadakis Al, Holcik M, Scheuner D et al. Phosphorylation of elF2alpha at serine 51 is an important determinant of cell survival and adaptation to glucose deficiency. Mol Biol Cell 2010; 21: 3220-3231.

42. Pelicano H, Carney D, Huang P. ROS. stress in cancer cells and therapeutic implications. Drug Resist Updat 2004; 7: 97-110.

43. Sarbassov DD, Sabatini DM. Redox regulation of the nutrient-sensitive raptor-mTOR pathway and complex. J Biol Chem 2005; 280: 39505-39509.

44. Yoshida S, Hong S, Suzuki T, Nada S, Mannan AM, Wang J et al. Redox regulates mammalian target of rapamycin complex 1 (mTORC1) activity by modulating the TSC1/ TSC2-Rheb GTPase pathway. J Biol Chem 2011; 286: 32651-32660.

45. Trachootham D, Zhou Y, Zhang H, Demizu Y, Chen Z, Pelicano H et al. Selective killing of oncogenically transformed cells through a ROS-mediated mechanism by beta-phenylethyl isothiocyanate. Cancer Cell 2006; 10: 241-252. 
46. Shaw AT, Winslow MM, Magendantz M, Ouyang C, Dowdle J, Subramanian A et al. Selective killing of K-ras mutant cancer cells by small molecule inducers of oxidative stress. Proc Natl Acad Sci USA 2011; 108: 8773-8778.

47. Leslie NR, Bennett D, Lindsay YE, Stewart H, Gray A, Downes CP. Redox regulation of PI 3-kinase signalling via inactivation of PTEN. EMBO J 2003; 22: 5501-5510.

48. Nemoto S, Finkel T. Redox regulation of forkhead proteins through a p66shc-dependent signaling pathway. Science 2002; 295: 2450-2452.

49. Wan X, Harkavy B, Shen N, Grohar P, Helman LJ. Rapamycin induces feedback activation of Akt signaling through an IGF-1R-dependent mechanism. Oncogene 2007; 26: 1932-1940.

50. Harrington LS, Findlay GM, Gray A, Tolkacheva T, Wigfield S, Rebholz H et al. The TSC1-2 tumor suppressor controls insulin-PI3K signaling via regulation of IRS proteins. J Cell Biol 2004; 166: 213-223.

51. Shah OJ, Wang Z, Hunter T. Inappropriate activation of the TSC/Rheb/mTOR/S6K cassette induces IRS1/2 depletion, insulin resistance, and cell survival deficiencies. Curr Biol 2004; 14: $1650-1656$.

52. Chiang GG, Abraham RT. Phosphorylation of mammalian target of rapamycin (mTOR) at Ser-2448 is mediated by p70S6 kinase. J Biol Chem 2005; 280: 25485-25490.

53. Holz MK, Blenis J. Identification of S6 kinase 1 as a novel mammalian target of rapamycin (mTOR)-phosphorylating kinase. J Biol Chem 2005; 280: 26089-26093.

54. Soliman GA, Acosta-Jaquez HA, Dunlop EA, Ekim B, Maj NE, Tee AR et al. mTOR Ser-2481 autophosphorylation monitors mTORC-specific catalytic activity and clarifies rapamycin mechanism of action. J Biol Chem 2010; 285: 7866-7879.

55. Copp J, Manning G, Hunter T. TORC-specific phosphorylation of mammalian target of rapamycin (mTOR): phospho-Ser2481 is a marker for intact mTOR signaling complex 2. Cancer Res 2009; 69: 1821-1827.

56. Sarbassov DD, Guertin DA, Ali SM, Sabatini DM. Phosphorylation and regulation of Akt/PKB by the rictor-mTOR complex. Science 2005; 307: 1098-1101.

57. Li S, Brown MS, Goldstein JL. Bifurcation of insulin signaling pathway in rat liver: mTORC1 required for stimulation of lipogenesis, but not inhibition of gluconeogenesis. Proc Natl Acad Sci USA 2010; 107: 3441-3446.

58. Ye J, Mancuso A, Tong X, Ward PS, Fan J, Rabinowitz JD et al. Pyruvate kinase M2 promotes de novo serine synthesis to sustain $\mathrm{mTORC} 1$ activity and cell proliferation. Proc Natl Acad Sci USA 2012; 109: 6904-6909.

59. Guan BJ, Krokowski D, Majumder M, Schmotzer CL, Kimball SR, Merrick WC et al. Translational control during endoplasmic reticulum stress beyond phosphorylation of the translation initiation factor elF2alpha. J Biol Chem 2014; 289: 12593-12611.

60. Wilson GJ, Bunpo P, Cundiff JK, Wek RC, Anthony TG. The eukaryotic initiation factor 2 kinase GCN2 protects against hepatotoxicity during asparaginase treatment. Am J Physio Endocrinol Metab 2013; 305: E1124-E1133.
61. Thedieck K, Holzwarth B, Prentzell MT, Boehlke C, Klasener K, Ruf S et al. Inhibition of mTORC 1 by astrin and stress granules prevents apoptosis in cancer cells. Cell 2013; 154: 859-874.

62. Kedersha N, Chen S, Gilks N, Li W, Miller IJ, Stahl J et al. Evidence that ternary complex (elF2-GTP-tRNA(i)(Met))-deficient preinitiation complexes are core constituents of mammalian stress granules. Mol Biol Cell 2002; 13: 195-210.

63. Zhang J, Kim J, Alexander A, Cai S, Tripathi DN, Dere R et al. A tuberous sclerosis complex signalling node at the peroxisome regulates mTORC1 and autophagy in response to ROS. Nat Cell Biol 2013; 15: 1186-1196.

64. Raj L, Ide T, Gurkar AU, Foley M, Schenone M, Li X et al. Selective killing of cancer cells by a small molecule targeting the stress response to ROS. Nature 2011; 475 : 231-234.

65. Gorrini C, Harris IS, Mak TW. Modulation of oxidative stress as an anticancer strategy. Nat Rev Drug Discov 2013; 12: 931-947.

66. Krishnamoorthy J, Rajesh K, Mirzajani F, Kesoglidou P, Papadakis Al, Koromilas AE. Evidence for elF2alpha phosphorylation-independent effects of GSK2656157, a novel catalytic inhibitor of PERK with clinical implications. Cell Cycle 2014; 13: 801-806.

67. Axten JM, Medina JR, Feng Y, Shu A, Romeril SP, Grant SW et al. Discovery of 7-methyl-5(1-\{[3-(trifluoromethyl)phenyl]acetyl\}-2,3-dihydro-1H-indol-5-yl)-7H-p yrrolo[2,3-d]pyrimidin4-amine (GSK2606414), a potent and selective first-in-class inhibitor of protein kinase $\mathrm{R}$ (PKR)-like endoplasmic reticulum kinase (PERK). J Med Chem 2012; 55: 7193-7207.

68. Sidrauski C, Acosta-Alvear D, Khoutorsky A, Vedantham P, Hearn BR, Li H et al. Pharmacological brake-release of mRNA translation enhances cognitive memory. Elife 2013; 2: e00498.

69. Huang S, Holzel M, Knijnenburg T, Schlicker A, Roepman P, McDermott U et al. MED12 controls the response to multiple cancer drugs through regulation of TGF-beta receptor signaling. Cell 2012; 151: 937-950.

(i) Cell Death and Disease is an open-access journal published by Nature Publishing Group. This work is licensed under a Creative Commons Attribution 4.0 International Licence. The images or other third party material in this article are included in the article's Creative Commons licence, unless indicated otherwise in the credit line; if the material is not included under the Creative Commons licence, users will need to obtain permission from the licence holder to reproduce the material. To view a copy of this licence, visit http://creativecommons.org/licenses/by/4.0 